Journal of Science and Technology Research

Journal homepage: www.nipesjournals.org.ng

\title{
Evaluating Usability of Academic Web Portals for Clearance Services
}

\section{F. O. Oliha}

Department of Computer Science, University of Benin, Benin City, Edo State

Email: oliha_festus@uniben.edu; Tel.: +234(0)8181664989

\begin{tabular}{l} 
Article Info \\
\hline Received 21 July 2020 \\
Revised 27 July 2020 \\
Accepted 29 July 2020 \\
Available online 31 August 2020 \\
\hline
\end{tabular}

\section{Keywords:}

Student Clearance, Clearance

Systems, Web Portal Usability,

Efficiency, Effectiveness, Satisfaction,

Web Technologies

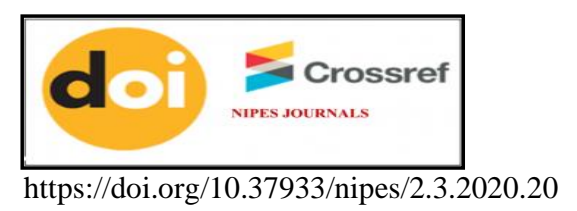

\begin{abstract}
Clearance services regarding outgoing or graduating students are deficient in most academic web portals and the few existing are prone to serious usability challenges. A framework for a cybernated clearance portal was proposed and implemented as an integral prototype system of the object study. Data were gathered and evaluated using a survey-based usability evaluation method. The resulting system was then evaluated by selected number of participants to determine its usability level in terms of effectiveness, efficiency, and satisfaction. Results indicated that participants of the experiment were of the perception that the system was satisfactorily easy to use with an average mean of 7.37 portraying the system usability satisfaction rate with the "Easy" level. This further affirmed that the developed system was easy to use (effective), facilitates task completion (efficient), and was preferred to their existing rigorous approach of executing graduate's clearance services.
\end{abstract}

\section{Introduction}

Most academic institutions have become organizationally productive with the use of web portal technologies in services involving students' admission, registration, payment, clearance, records, results and many more $[1,2,3]$. Clearance in particular, is required for both entry and outgoing students in all academic institutions. In so doing, web portal technologies have been adopted towards managing students related services.

Despite the technological efforts, graduating students' clearance has remained manual in most tertiary institutions and this has ventured the advocacy of automating the processes in learning institutions. A recent study revealed the development of a few clearance systems but mostly relegated to the non-use category [4]. Developing a web portal system particularly for student information management without considering the ease to use, learn and complete a task results to serious usability challenges [5]. Usability factor is a vital determinant that may influence users' intentions to use a software application or product and should be evaluated when developing academic clearance systems. Owing to this, this paper first, explored background information and proposes a framework in section 2. Section 3 designed and implemented the framework as a prototype module for integration into the observed institutions web portal. This developed prototype was evaluated and results were discussed with respect to usability factors ascertaining its effectiveness, efficiency and satisfaction in section 4, and thereafter concluded in section 5. 


\section{Background Knowledge}

Universities are now confident in web technologies as institutional tools to manage all students related activities. Clearance activities are now managed via web portal technologies, and these technologies have overtime proven to be significant as tools for complex amount of student data management. Studies have shown that clearance is a vital, hectic and tedious exercise for both entry and outgoing students and efforts have been advocated toward automating graduating students' clearance processes with the development of web applications $[2,3,6,7,8]$. It is still a grey area to ascertain the usability of these developed applications as Eti [4] argued that, they have either been neglected or relegated to the background. The non-acceptance nor usage issue is bound to usability challenges that may be accrued from the developer perspectives in failure to consider users preferences at design stages [9] and, several usability factors including the system's efficiency, effectiveness, satisfaction, learnability, etc. [4,10,11,12].

Most of these clearance web portals, even though they might have met all scientific and technical design requirements [5] have not been evaluated against system usability attributes: effectiveness, efficiency and user satisfaction - which according to Aziz [13], is the ability to gauge that the portals are fulfilling their objectives in order for stakeholders to measure planned improvements on the portal and their desired impacts. However, usability of clearance systems needs to be evaluated to account for desired impacts.

Usability is the measure of ease with which a system can be learned or used, its safety, effectiveness and efficiency, and the attitude of its users towards it [5]. The ease being the extent to which a web portal system can be used by students or staff to achieve specific tasks with effectiveness, efficiency, rate of errors, memorability and satisfaction in a specific context of use $[5,14,15$,$] . Usability is an$ important determinant of quality in software products, as it has overtime been established, that the success or failure of software products does not only depend on a completed set of functionalities but on quality which is evaluated by usability $[16,17,18]$. Thus, usability ensures that a system must be useful, usable and used. In this paper, a framework was proposed, implemented and the developed prototype was a cybernated clearance system evaluated with regards three usability attributes - effectiveness, efficiency and satisfaction. The proposed framework, design and implementation were described in section 3 hereafter.

\section{Methodology}

\subsection{The Proposed Conceptual Framework}

The proposed conceptual framework for the clearance system depicted in Figure 1, is a formal representation of the intending system which comprises of the externally visible components of the system organized in a way that supports implementation of the overall system. It depicts the interactions between the users with the system, how information is generated and flow through the system. The observed study was University of Benin web portal. 


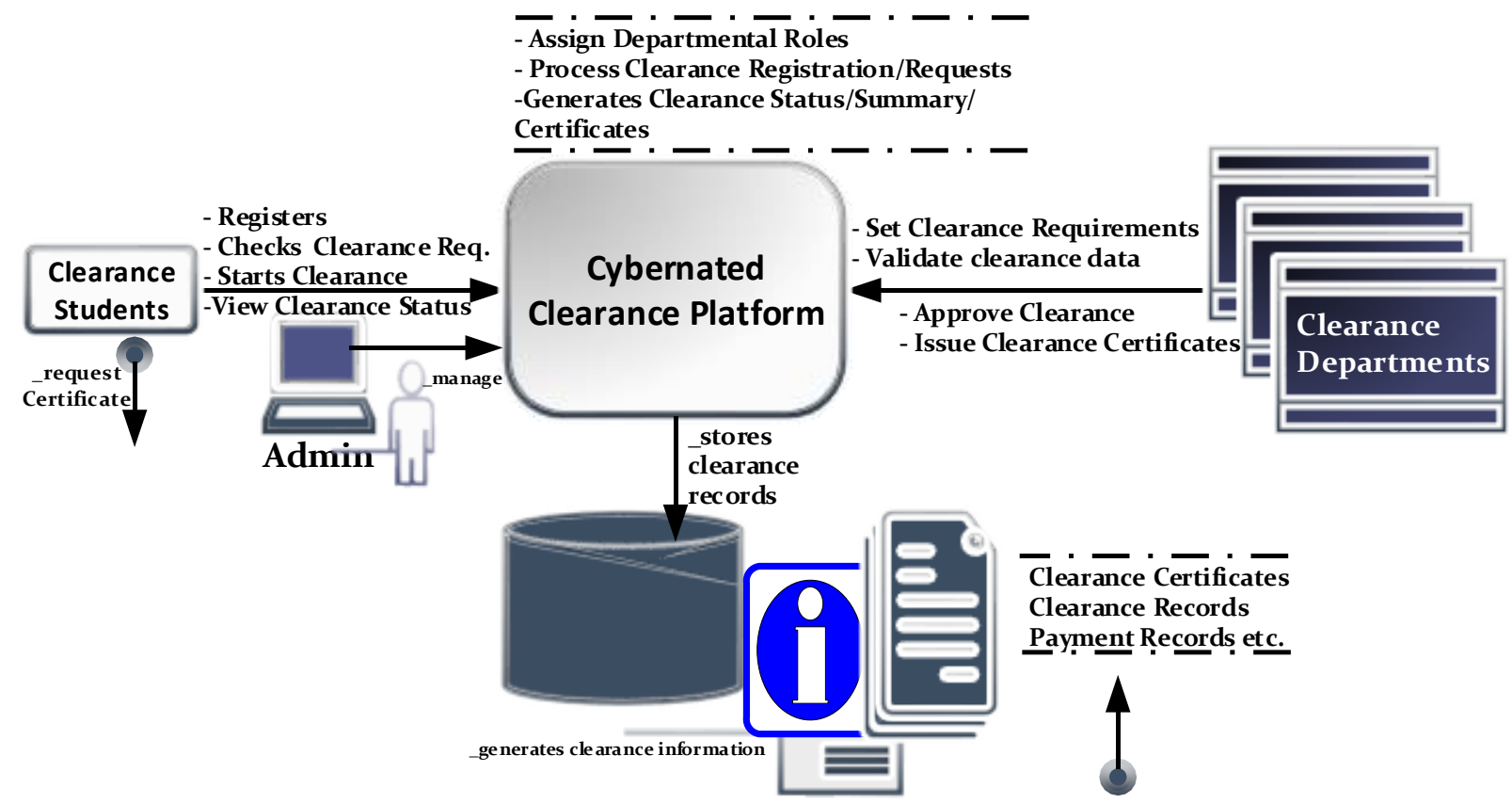

Figure 1. A Framework for a Cybernated Clearance System

The model consists of simple diagrams representing entities or component of the system and arrows showing the roles or activities associated with each entity. The clearance processes depicted here, begins with the system admin creating users account for each departmental clearance officers and thereafter, the clearance staff at the departmental level uploads approved graduating students list, and students can then go to the clearance module to register, login, check clearance requirement and start clearance by uploading their required clearance documents as depicted in Figure 2, with approved payment clearance records, they can request for clearance certificate once their status is deemed cleared by clearance officers. On the other hand, each departmental clearance officers Departmental Clearance, Faculty Clearance, Student Affairs, etc. is saddled with roles to facilitate the process from one stage to another. Each is authorized into the system via a user login accordingly. The system generates and stores records in the database in order to produce the expected deliverables. Deliverables from the system are student's clearance records, certificates, printouts amongst others as they apply to various departments.

\subsection{Information Flow Design}

Depicted in Figure 2 is a detailed or level 2 Data Flow Diagram (DFD) which captures the flow of information and entities of the system to be developed. It aids the description of processes and information flow in systems. 


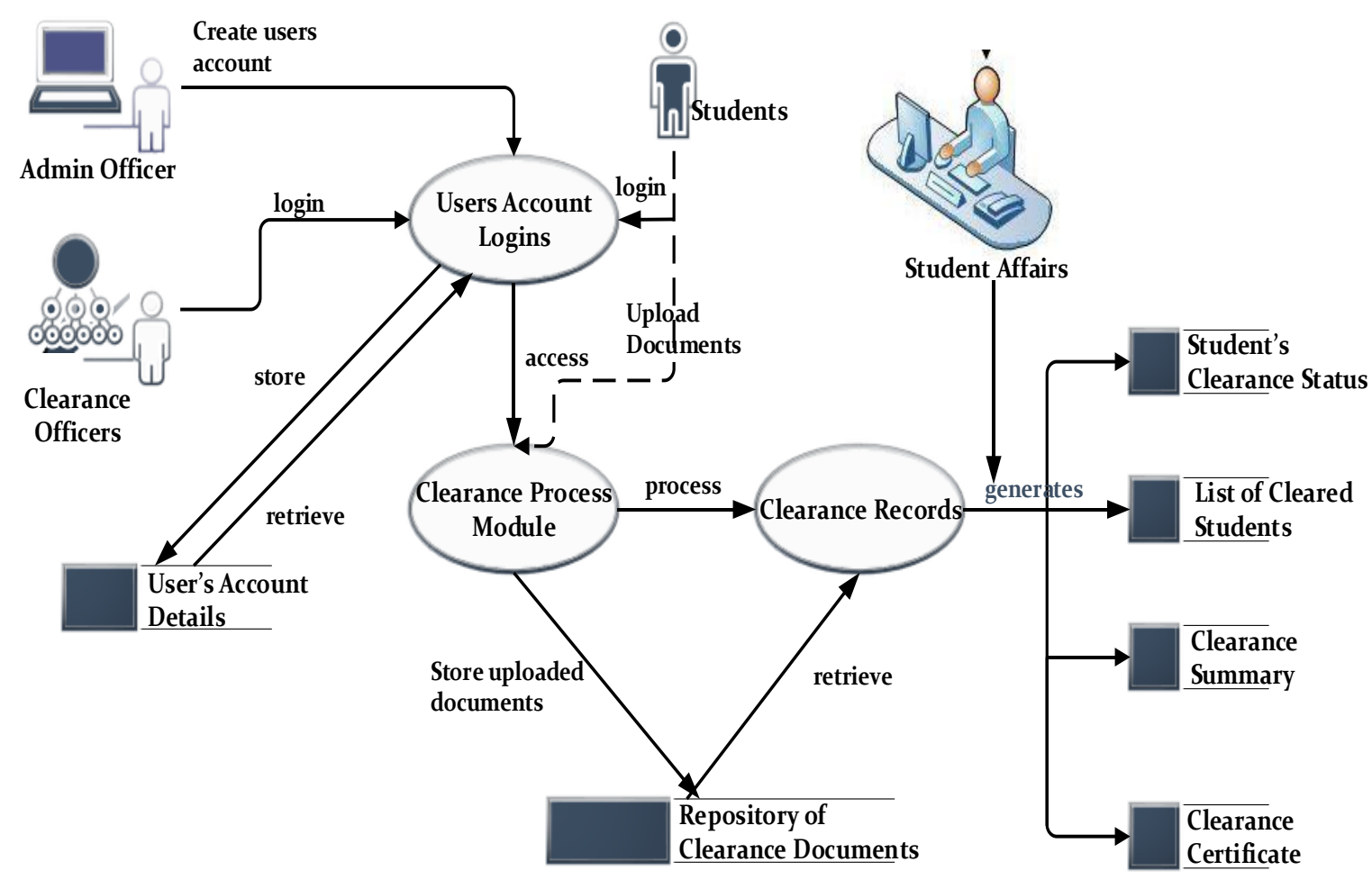

Figure 2. A Detailed DFD for the Proposed Cybernated Clearance System

The design is made up of several entities, processes and deliverables. It further highlighted the functionalities of the framework for better understanding showing the flow of information, the processes, repositories and deliverables towards implementation of the system.

\subsection{Implementation and Deployment}

Technically, implementation entails the systematic conversion of designs into a working system via software development tools and testing the developed cybernated clearance modules according to users' preferences or needs. Owing to this, PHP, a server-side scripting language for building dynamic web pages was used in coding scripts which were embedded into HTML source documents and interpreted by a web server with PHP preprocessor model. Cascading Style Sheets (CSS), a style sheet language was used for describing the user interfaces and layout formatting of a documents written in a markup language. JavaScript was employed for the systems interactive interfaces and forms validation, and to support content production for all modern web browsers without plug-ins. The major schema objects were created in the database as tables to store clearance data for the resultant system using MySQL as a custom storage engine. The database was fully accessed using PHP connection from the Application Programming Interface (API) to the backend provided by the phpMyadmin component of MySQL Server. Other supporting technologies include: Bootstrap frontend framework, JQuery.js, Asynchronous JavaScript and XML (AJAX). XAMPP a cross platform server technology was used as a local server to deploy the system. A home interface of the developed system is depicted in Figure 3. 


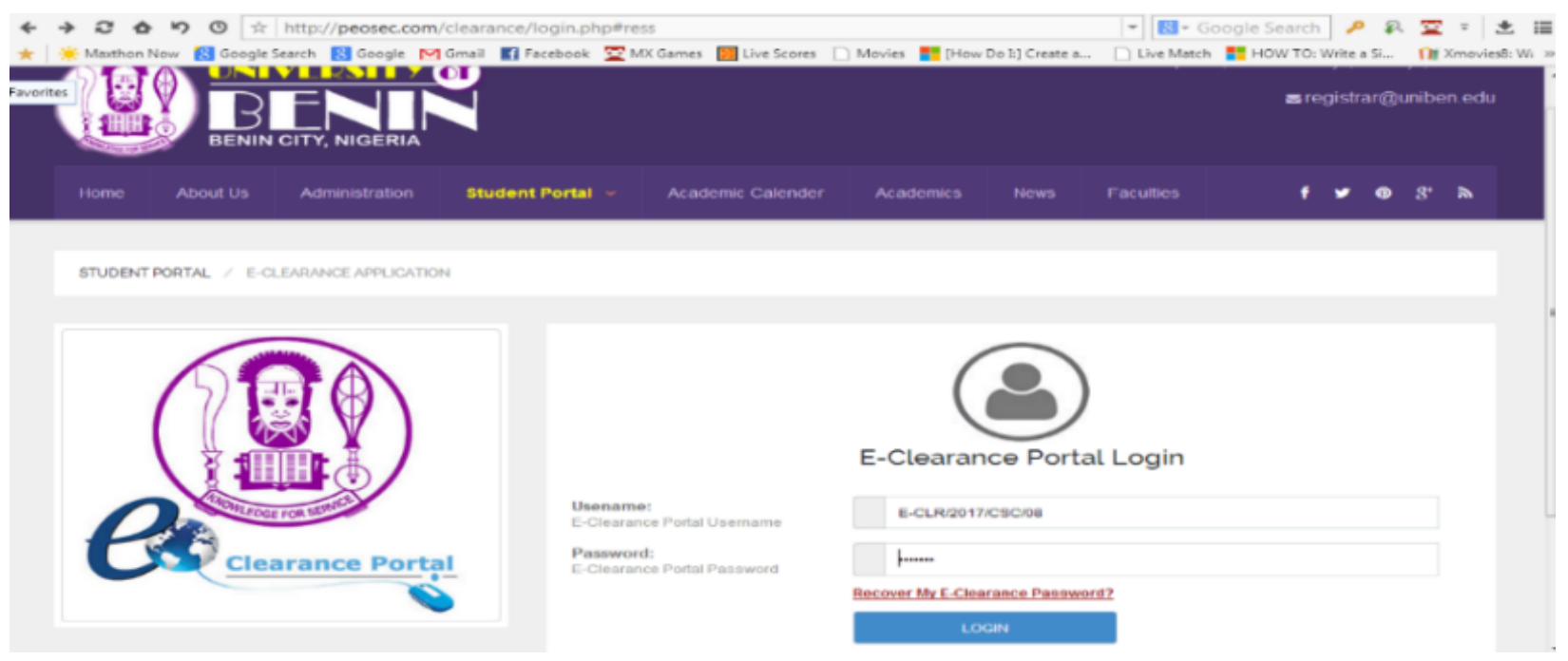

Figure 3. Home Page of the Cybernated Clearance Portal system

\section{Evaluation and Results}

The evaluation procedure was in stages involving different tasks and participants. There were seven clearance related tasks and eighteen participants made up of seven departmental clearance officers and eleven students of various faculties. The goal was to examine the system's usability and the number of evaluators (participants) is quite adequate in range with regards to software usability evaluation $[19,20]$.

Usability testing was conducted to evaluate the ease at which the system can be used in a specific context. It was measured using standard metrics: efficiency, effectiveness and satisfaction [5,18,21]. The usability experiments were explained to the participants with guidelines on how to use the system to complete a specific task. A survey-based usability evaluation method was adopted [17] with adapted questions scaling from $1-10$ representing "very difficult" to "very easy" in order to capture usability test outcomes.

Data were gathered from the experiment via logs of the participants interactions with the clearance system. The log contained details of each participant and their usability ratings on different tasks. Each was recorded with start time, finish time and the level of completeness reached with every task. Some tasks were separately handled by the students while others by the clearance officials. The results of the evaluation are represented in tables regarding the system's effectiveness, efficiency and users' satisfaction.

\subsection{Effectiveness}

Effectiveness measures the outcome of the participants interaction or use with the system. In this paper, it indicates the completion rate. The participants average task completion rates were extracted and presented in Table 1, demonstrating the effectiveness of the system.

Table 1: Task Completion Evaluation Ratings

\begin{tabular}{|l|l|l|l|l|l|}
\hline $\mathbf{S} / \mathbf{N}$ & Tasks & $\begin{array}{l}\text { Participants } \\
\text { Staff } \\
(\text { Mean) }\end{array}$ & $\begin{array}{l}\text { Student } \\
\text { (Mean) }\end{array}$ & STD & $\begin{array}{l}\text { Usability } \\
\text { Rate }\end{array}$ \\
\hline $\mathbf{1}$ & Register and login & 6.7143 & 6.5455 & 1.3779 & 6.6299 \\
\hline $\mathbf{2}$ & Upload clearance documents & 7.0000 & 7.8182 & 1.0553 & 7.4091 \\
\hline $\mathbf{3}$ & Make payments & - & 4.8182 & 2.0405 & 4.8182 \\
\hline $\mathbf{4}$ & Edit, save or view clearance status & 6.5714 & 7.7273 & 1.0178 & 7.1494 \\
\hline
\end{tabular}




\begin{tabular}{|l|l|l|l|l|l|}
\hline $\mathbf{5}$ & Validate and confirm payments & 6.8571 & - & 0.8997 & 6.8571 \\
\hline $\mathbf{6}$ & Issue, request and print clearance & 7.0000 & 7.9091 & 1.0416 & 7.4545 \\
\hline $\mathbf{7}$ & Complete clearance task and logout successfully & 7.2857 & 8.0000 & 0.9582 & 7.6429 \\
\hline Overall & $\mathbf{6 . 9 0 4 8}$ & $\mathbf{7 . 1 3 6 4}$ & $\mathbf{1 . 1 9 8 7}$ & $\mathbf{6 . 8 5 1 6}$ \\
\hline
\end{tabular}

\subsection{Efficiency}

Efficiency is the time resources used by participants in completing a task. It shows the time to complete each task and it can be calculated in two ways; time based and overall relative. The overall relative was adopted in this paper because it is more suitable regarding the multiple tasks. The time rate at which each task was completed by the participants was obtained using the Equation (1) [19]: Overall Relative Efficiency $(\mathrm{ORE})=\frac{\sum_{i=1}^{R} \sum_{j=1}^{N} n_{i j} t_{i j}}{\sum_{i=1}^{R} \sum_{j=1}^{N} t_{i j}} \times 100 \%$

From Equation (1): $\mathbf{N}$ is the tasks to be completed, $\mathbf{R}$ is the number of participants, $\mathbf{t}_{\mathbf{i j}}$ is the completion time of task $\mathbf{i}$ by participant $\mathbf{j}, \mathbf{n}_{\mathbf{i j}}$ is the outcome of task $\mathbf{i}$ by participant $\mathbf{j} ; \mathbf{n}_{\mathbf{i j}}=\mathbf{1}$ : if the task $\mathbf{i}$ was completed by all participants $\mathbf{j}$, otherwise it is divided by the number of those who completed theirs over the entire participants. The ORE is the ratio of effective users' work time to all users' work time as summarized in Equation (1). Thus:

for Task $1, \mathrm{~N}=1, \mathrm{R}=18, \mathbf{n}_{\mathbf{i j}}=1, \mathbf{t}_{\mathbf{i j}}=1.23$, and $n_{i j} t_{i j}=1.23$;

for Task $2, \mathrm{~N}=1, \mathrm{R}=12, \mathbf{n}_{\mathrm{ij}}=0.6667, \mathbf{t}_{\mathrm{ij}}=2.5$, and $n_{i j} t_{i j}=1.6667$;

for Task $3, \mathrm{~N}=1, \mathrm{R}=11, \mathbf{n}_{\mathrm{ij}}=0.6111, \mathbf{t}_{\mathbf{i j}}=2.44$, and $n_{i j} t_{i j}=1.4911$;

for Task $4, \mathrm{~N}=1, \mathrm{R}=18, \mathbf{n}_{\mathrm{ij}}=1, \mathbf{t}_{\mathrm{ij}}=1.33$, and $n_{i j} t_{i j}=1.33$;

for Task 5, $\mathrm{N}=1, \mathrm{R}=7, \mathbf{n}_{\mathrm{ij}}=0.3889, \mathbf{t}_{\mathrm{ij}}=3.09$, and $n_{i j} t_{i j}=1.2017$;

for Task $6, \mathrm{~N}=1, \mathrm{R}=18, \mathbf{n}_{\mathrm{ij}}=1, \mathbf{t}_{\mathrm{ij}}=1.38$, and $n_{i j} t_{i j}=1.38$;

for Task $7, \mathrm{~N}=1, \mathrm{R}=18, \mathbf{n}_{\mathrm{ij}}=1, \mathbf{t}_{\mathrm{ij}}=1.49$, and $n_{i j} t_{i j}=1.49$;

$\sum_{i=1}^{R} \sum_{j=1}^{N} n_{i j} t_{i j}=9.78944 ; \quad \sum_{i=1}^{R} \sum_{j=1}^{N} t_{i j}=13.49 ; \quad$ ORE $=72.75 \%$

\subsection{Satisfaction}

Satisfaction indicates the ease, comfort and difficulty at which participants used the clearance system. In this paper, the test level satisfaction was opted for using the post task questions. Table 2 captures the average participants post system's satisfaction ratings on usability level.

Table 2: Satisfaction Evaluation Ratings

\begin{tabular}{|l|l|l|l|l|l|l|}
\hline S/N & Tasks & $\begin{array}{l}\text { Participants } \\
\text { Staff } \\
\text { (Mean) }\end{array}$ & $\begin{array}{l}\text { Student } \\
\text { (Mean) }\end{array}$ & STD & Mean & Usability Level \\
\hline $\mathbf{1}$ & Overall scale on Task 1 & 8.0000 & 7.8182 & 0.9003 & 7.9091 & Easy \\
\hline $\mathbf{2}$ & Overall scale on Task 2 & 6.0000 & 8.3636 & 1.0299 & 7.1818 & Easy \\
\hline $\mathbf{3}$ & Overall scale on Task 3 & - & 5.8182 & 0.7506 & 5.8182 & Moderate \\
\hline $\mathbf{4}$ & Overall scale on Task 4 & 7.4286 & 7.9091 & 0.6691 & 7.6688 & Easy \\
\hline $\mathbf{5}$ & Overall scale on Task 5 & 7.5714 & - & 0.5345 & 7.5714 & Easy \\
\hline $\mathbf{6}$ & Overall scale on Task 6 & 7.8571 & 7.8182 & 0.7071 & 7.8377 & Easy \\
\hline $\mathbf{7}$ & Overall scale on Task 7 & 7.2857 & 7.9091 & 0.5941 & 7.5974 & Easy \\
\hline Overall & & $\mathbf{7 . 3 5 7 1}$ & $\mathbf{7 . 6 0 6 1}$ & $\mathbf{0 . 7 4 0 8}$ & $\mathbf{7 . 3 6 9 2}$ & Easy \\
\hline
\end{tabular}




\subsection{Discussion of Results}

The results of the evaluation were presented and rated with the Likert scale in Table 3.

Table 3. Usability Rating Scale

\begin{tabular}{|c|c|c|}
\hline SN & Average Usability Rating & Indication \\
\hline $\mathbf{1}$ & $0.00 \leq U L \leq 2.00$ & Very Difficult \\
\hline $\mathbf{2}$ & $2.00 \leq U L \leq 4.00$ & Difficult \\
\hline $\mathbf{3}$ & $4.00 \leq U L \leq 6.00$ & Moderate \\
\hline $\mathbf{4}$ & $6.00 \leq U L \leq 8.00$ & Easy \\
\hline $\mathbf{5}$ & $8.00 \leq U L \leq 10.00$ & Very Easy \\
\hline
\end{tabular}

Table 1 shows the evaluation ratings for task completion by both categories of the participants. The average completion rate for each task was computed for both the clearance officials and students. Results revealed that the task of making payments was rated moderate with an average rating of 4.82 - an indication that payment is not directly an internal component of the system, but there was an indication that participants were most comfortable in executing a clearance task and logged out successfully with an average rating of 7.64. With a standard deviation of 1.20 and average mean of 6.85 , the system falls in the range of "Easy". This is an indication that the cybernated clearance system can be effectively used with ease for completing clearance tasks.

The resources in time consumed in completing a task was evaluated in terms of overall relative efficiency. Due to its suitability for multi tasks, results revealed that the overall relative efficiency was $72.8 \%$ - which indicates that the developed clearance system is highly efficient in executing clearance tasks.

Evaluation ratings for the usability attribute of satisfaction were captured in Table 2, the average usability satisfaction mean of 7.91 and 7.84 indicated that participants found the system satisfactorily easy on task 1 and task 6. The average satisfaction mean for clearance officials was 7.36 with a usability level of "Easy" - another indication that the system is satisfactorily easy to use. This is a huge relief from the existing rigorous clearance burden. On the aspect of students, an average mean of 7.61 portraying their satisfaction level with the "Easy" usability level. They now prefer the system to the former as they are no longer saddled with the rigorous activities of moving from one clearance office to another. There is an overall indication that the participants of this study were of the perception that the system is satisfactorily easy to use with an average mean of 7.37 with a standard deviation of 0.74 .

\section{Conclusion}

This research is a pioneer study in evaluating the usability of web portal technologies for clearance activities of outgoing students of tertiary institutions. Summarily, the results obtained revealed that the developed clearance system is effective, efficient and satisfactorily easy to use - that is, it is usable, can be used and very useful for clearance related tasks. In the light of usability, web technologies should be harnessed to develop and deploy portal systems with optimal ease for efficient and effective use to enhance stakeholder productivity and facilitate clearance related services for graduating students. The significance of this study will act as a signal and scale for academic institutions to gauge their investments in academic web portal systems and also, to review usability efforts in the development cycle. 


\section{References}

[1] F.O. Oliha (2014). Web Portal usability among Nigerian University Students: A case study of University of Benin, Nigeria. Nigerian Journal of Technology, pp $199-206$.

[2] O. Agbo-Ajala, and O. E. Makinde (2015). A Web-Based Database-Driven Students' Clearance System. International Journal of Advanced Research in Computer Science and Software Engineering, Vol 5, Issue 7, pp $65-69$.

[3] O. L. Usman, O. O. Olusanya and O. B. Adedeji (2016). Design and Development of Online Clearance System for Tertiary Institutions: A Case Study of Tai Solarin University of Education, Ogun State, Nigeria. Proceedings of the iSTEAMS Multidisciplinary Cross-Border Conference, University of Professional Studies, Accra Ghana, pp 655-664.

[4] F. I. Eti (2018). The Application of Unified Theory of Acceptance and Use of Technology (UTAUT) in Assessing Student Clearance System. International Journal of Innovative Mathematics, Statistics \& Energy Policies, Vol 6, No 2, pp 12-16.

[5] N. F. M. EL-firjani, E. K. Elberkawi and A., M. Maatuk (2017). A Method for Website Usability Evaluation: A Comparative Analysis. International Journal of Web \& Semantic Technology (IJWesT) Vol.8, No.3, pp 111.

[6] F.E. Idacahaba, K.E. Mbeh, O.I. Oshin and O.O. Oni (2015). Webportal Applications: Automated Student Clearance Portal, Proceedings of the World Congress on Engineering, Vol 1, pp 978-988.

[7] B. Umezinwa, C. Henry, and A. Iriaoghuan (2015). Design and Implementation of Online Clearance System: A case study of Imo State, University European Journal of Applied Sciences, Vol 1, pp 25 - 31

[8] L. Cadiz III, C. N. Bondoc, and J. Estroga (2017). Moving Towards Global Technological Advancement: Basis for the E-Clearance Program Development. International Journal of Computing Academic Research (IJCAR), Vol 6, No 6, pp 171-179.

[9] G. R. El Said (2018). The Intention to Use Mobile Student Portal: A Mobile Human Computer Interaction Study in a University Context in Egypt. Mobile Information Systems, Hindawi, pp1-8.

[10]R. P. Bringular and R. S. Basa (2011). Factors Affecting Faculty Web Portal Usability. Educational Technology and Society, Vol 14, No. 4, pp 253-265.

[11] S. S. Alam, M. D. Ismail, M. H. Ali, and Z. Zain (2017). Factors Influencing Students' Usage Satisfaction Toward University Web Portal: A Pls-Sem Analysis. Jurnal Personalia Pelajar, Vol 20, No. 2, pp 11-22.

[12] S. S. T. Alatawi, N. S Abdullah. and, S. Miskon (2018). Factor Effect on Saudi Students to Use University Portal in Saudi Arabia. Journal of Engineering and Applied Sciences Vol 13, Special Issue 6, pp 5435-5441.

[13]N. A. B. Aziz. (2015). Exploring the Factors Influencing UteM's Portal Effectiveness. Thesis, Universiti Teknikal Malaysia Melaka (UTeM). 24pp.

[14]E. Froekjaer, M. Hertzum, and, H. Hornbark (2000). Measuring Usability: Are Effectiveness, Efficiency, and Satisfaction Really Correlated? Chi letters. Vol 2, Issue 1, pp 345-352.

[15]H. M. K. Abdoasslam (2016). Measuring Usability for Application Software Using the Quality in Use Integration Measurement Model. MSc Thesis, Universiti Tun Hussein Onn Malaysia, 42pp.

[16] A. Abran, A. Khelifi, W. Suryn, and A. Seffah (2005). Consolidating the ISO Usability Models, pp 1-17.

[17]H. Hayat, R. Lock and I. Murray (2019). Measuring Software Usability. Figshare, available @ https://hdl.handle.net/2134/18275

[18] C. P. C. Munaiseche, and O. E. S. Liando (2016). Evaluation of expert system application based on usability aspects. International Conference on Innovation in Engineering and Vocational Education, IOP Conference Series: Materials Science and Engineering 128, IOP, pp 1-10.

[19] R. Macfield, (2009). How to Specify the Participant Group Size for Usability Studies: A Practitioner's Guide, Journal of Usability Studies, Vol 5. No. 1. pp. 34-35.

[20] J. M. Six, \& R. Macfield (2016). How to Determine the Right Participants for Usabiity Studies, UX Matters, available at https://www.uxmatters.com/mt/archives/2016/01/how-to-determine-the-right-participants-forusabiity-studies.php

[21] J. Mifsud (2015). Usability Metrics - A Guide to Quantify the Usability of Any System. Usability Geek. Available @ https://usabilitygeek.com/usability-metrics-a-guide-to-quantify-system-usability. 